\title{
Hormonal, Metabolic, and Cardiorespiratory Responses of Young and Adult Athletes to a Single Session of High-Intensity Cycle Exercise
}

\author{
Florian Engel and Sascha Härtel \\ Karlsruhe Institute of Technology
}

\author{
Jana Strahler \\ University of Marburg
}

\author{
Matthias Oliver Wagner \\ University of Konstanz
}

\author{
Klaus Bös \\ Karlsruhe Institute of Technology
}

\section{Billy Sperlich \\ Julius-Maximilians University of Würzburg}

\begin{abstract}
This study aimed to determine the effects of a single high-intensity interval training (HIIT) session on salivary cortisol (SC) levels, physiological responses, and performance in trained boys and men. Twenty-three boys ( $11.5 \pm 0.8$ years) and 25 men ( $29.7 \pm 4.6$ years) performed HIIT ( 4 consecutive Wingate Anaerobic Tests). $\mathrm{SC}$ in boys and men increased after HIIT from $5.55 \pm 3.3 \mathrm{nmol} / 1$ to $15.13 \pm 9.7 \mathrm{nmol} / \mathrm{l}(+173 \%)$ and from 7.07 $\pm 4.7 \mathrm{nmol} / \mathrm{l}$ to $19.19 \pm 12.7 \mathrm{nmol} / \mathrm{l}(+171 \%)$, respectively $(p<.01)$. Pretest SC as well as posttest changes were comparable in both groups (both $p<.01$ ). Peak blood lactate concentration was significantly lower in boys $(12.6 \pm 3.5 \mathrm{mmol} / \mathrm{l})$ than in men $(16.3 \pm 3.1 \mathrm{mmol} / \mathrm{l} ; p<.01)$. Throughout the HIIT, mean heart rates in boys were higher $(p<.001)$ but relative peak oxygen uptake $\left(\mathrm{ml} \cdot \mathrm{min}^{-1} \cdot \mathrm{kg}^{-1} ; p<.05\right)$ and performance were lower $(p<.001)$ in boys than in men. HIIT in young athletes is associated with a higher activation of the hormonal stress axis than other types of exercise regimes as described in the literature. This study is the first to show a pronounced SC increase to HIT in trained boys accompanied by elevated levels of blood lactate concentrations and heart rate suggesting a high cardio-respiratory, metabolic, and hormonal response to HIIT in 11-year-old boys.
\end{abstract}

Keywords: high-intensity interval training, salivary cortisol, children, catabolic hormones

In the past decade, high-intensity interval training (HIIT) has received great scientific interest and is considered an effective training method for metabolic adaptations $(8,20,31)$ and enhancing athletic performance (25). HIIT has been shown to increase maximal oxygen uptake $\left(\mathrm{VO}_{2 \max }\right)$, maximum strength, $10 \mathrm{~m}$ sprint time, and jump height in adult elite athletes (25) as well as enhancing $\mathrm{VO}_{2 \max }$, lactate threshold and soccer perfor-

Engel and Bös are with the Research Centre for School Sports and the Physical Education of Children and Adolescents, and Härtel the Institute of Sports and Sports Science, Karlsruhe Institute of Technology, Karlsruhe, Germany. Wagner is with the Division of Sport Science, University of Konstanz, Konstanz, Germany. Strahler is with the Dept. of Psychology, University of Marburg, Marburg, Germany. Sperlich is with the Institute of Sport Science, Julius-Maximilians University of Würzburg, Würzburg, Germany. Address author correspondence to Florian Engel at engel@foss-karlsruhe.de. mance in junior athletes $(24,33)$. In very young athletes HIIT improved $\mathrm{VO}_{2 \max }$, sprint performance, $1000 \mathrm{~m}$ running time (46), peak oxygen uptake $\left(\mathrm{VO}_{2 \text { peak }}\right)$ as well as maximal lactate accumulation and competition performance $(42,47)$.

Besides its ergogenic effect, there is also evidence that HIIT may produce unfavorable effects: HIIT performed with high physical exertion and over a longer period may, for example, lead to suppressed immune function caused by inhibition of T-cell function with altered blood concentrations of lymphocyte subsets (35). HIIT-induced elevated levels of stress hormones such as, epinephrine and cortisol are discussed as possible mediators of this effect $(35,44)$. Recent findings in adolescent athletes confirm increases of both anabolic and catabolic hormones following intense volleyball practice (17). However, data on the response of hormonal stress markers in children following HIIT is lacking. The recently introduced allostatic load model (32) might serve as a theoretical framework to explain negative 
health consequences of HIIT in children. According to this concept, frequent exposure of children to HIIT is considered an allostatic load condition. Allostatic load characterizes the wear and tear of allostatic systems, such as the hypothalamus-pituitary-adrenal (HPA) axis or the autonomic nervous system (ANS), repeatedly exposed to stressful environmental demands requiring adaptation. Children performing regular high-intensity exercise may be exposed to a chronic catabolic hormonal stress level and do not habituate to this kind of physical stressor. Thus, chronic HIIT can serve as repeated "hits" and "lack of adaptation," described in the allostatic load model, and is assumed chronic stress related to long term negative health effects. To understand the hormonal responses of children to HIIT and possibly evaluate HIIT related health concerns, it is important to understand the acute and short term responses of allostatic systems, the HPA axis in particular, to HIIT. Up to now, no data regarding stress hormones in children following HIIT has yet been published. Further, childhood is a sensitive period of development, and hence understanding the underlying metabolic and hormonal responses to HIIT in children is critical.

Recently, salivary concentration of cortisol, the main end product of the HPA axis, has emerged as an important biomarker for the psycho-physiological stress response (28) associated with prolonged (51) as well as high-intensity exercise $(29,52)$ in adults, adolescents $(21)$ and young children $(4,5,7)$. Salivary cortisol has been widely confirmed to be a valid and reliable indicator of the biological active and free fraction of cortisol levels (28) and corresponds well to serum cortisol levels both at rest and after exercise (37). For instance, salivary cortisol levels were elevated after a cycling above $70 \%$ of $\mathrm{VO}_{2 \text { peak }}$ in men (37), after a running above $70 \%$ of peak heart rate $\left(\mathrm{HR}_{\text {peak }}\right)$ in 14-year-old boys and girls (6), and during incremental cycling in 17-year-old boys (21). However, information on the hormonal response to physical exercise in children is scarce and data on the hormonal response to HIIT is lacking $(4,5,9,44)$.

Exercise induced hormonal responses differ between highly fit and average fit children (4): saliva cortisol levels after 20-m shuttle run tests were higher in highly fit compared with average fit children (4). In contrast, saliva cortisol concentrations did not increase after 12 min of intensive running in 9- to 10-year-old sedentary boys and girls (7).

In adults, HIIT leads to acute increased levels of plasma cortisol following 1 session of HIIT (52) and chronically elevated levels of plasma and salivary cortisol have been associated with decreased immune function $(10,36)$. Exercise-induced changes in levels of epinephrine and cortisol could underlie this effect (35). In contrast, acute responses of cortisol to HIIT in prepubertal children remain unknown. Since prepubertal children have distinct anthropometric, hormonal and metabolic properties than adults, differences between children's' and adults' hormonal and metabolic responses to HIIT are assumed. Investigating acute physiological and hormonal responses to HIIT in children will help to understand the short-term response of the HPA axis to this highly relevant physical stressor assumed to be related to health constraints in this age group.

Therefore, the main purpose of this study was to assess the physiological responses to a single HIIT session in prepubertal children and to compare the acute effects to those of adults. As it has been shown that trained adults respond to HIIT with increased cortisol concentrations (52) and children with lower blood lactate concentrations $(3,41)$ and fewer signs of muscle fatigue $(19,43)$ when compared with adults, we hypothesized that 1) increased cortisol concentrations will be observed in trained boys following a single HIIT session (consisting of 4 consecutive Wingate Anaerobic Tests), and 2) lower cortisol concentrations will be observed in trained boys than adult males following a single HIIT session.

\section{Methods}

\section{Participants}

Twenty-three healthy boys (mean $\pm S D, 11.5 \pm 0.8$ years) from a youth talent academy of a local soccer club (U12) and 25 healthy athletic trained male adults $(29.7 \pm 4.6$ years) from another local club participated in this study. The participants' age, selected anthropometric variables, peak oxygen uptake, and training workload at baseline are shown in Table 1. This study was conducted in accordance to the Declaration of Helsinki and its protocol was preapproved by the local ethical committee of the Karlsruhe Institute of Sports and Sports Science. All participants or their legal guardians signed an informed consent form after being informed about the potential risks and benefits of study procedures. The inclusion criteria for study participation for the boys and adults were 3 training sessions of systematic and specialized training (at least $1 \mathrm{hr}$ per session) per week to ensure similar training and fitness status and regular participation in competitions throughout the past 2 years. Exclusion criteria were any chronic or acute mental or physical impairment assessed by questionnaire and consumption of any pharmaceutical substances (eg, Ritalin).

\section{Experimental Design}

All participants were fully familiarized and habituated with the HIIT protocol, the exercise testing procedures and have previously been involved in other studies at the same laboratory. To minimize the effects of prior exercise or stress upon arrival, all participants rested in a sitting position for $30 \mathrm{~min}$ in a calm room under supervision. The general study design involved 4 bouts of 30-s all-out sprint cycles (Wingate Anaerobic Test; 26 ) followed by a 2-min active recovery after every 30 -s sprint. Sprint cycles were conducted on an electronically braked ergometer (Schoberer Rad Messtechnik GmbH, Jülich, Germany). The Wingate Anaerobic Test is highly reliable (test-retest reliability (intraclass coefficient): 
Table 1 Mean \pm SD of Anthropometric Data, $\mathrm{VO}_{2 \max }$, and Training Workload in Boys and Men

\begin{tabular}{lccc}
\hline $\boldsymbol{n}$ & Boys & Men & \multicolumn{2}{c}{ Effect size } \\
Age (yrs) & $\mathbf{2 3}$ & $\mathbf{2 5}$ & 5.51 \\
Height (cm) & $11.5 \pm 0.8^{*}$ & $29.7 \pm 4.6$ & 4.75 \\
Body mass (kg) & $149.3 \pm 6.6^{*}$ & $179.5 \pm 6.1$ & 5.69 \\
Tanner's stages (a.u.) & $38.5 \pm 6.7^{*}$ & $76.1 \pm 6.5$ & NA \\
Lean body mass (g) & $2.3 \pm 0.4$ & $\mathrm{NA}$ & 5.64 \\
Body fat (\%) & $33.2 \pm 5.0^{*}$ & $64.7 \pm 6.1$ & 0.82 \\
VO ${ }_{\text {2peak }}(\mathrm{ml} / \mathrm{min} / \mathrm{kg})$ & $8.2 \pm 4.6$ & 0.71 \\
Training workload (hrs/week) & $9.5 \pm 2.9$ & $47.3 \pm 8.2$ & 1.12 \\
Training frequency (sessions/week) & $42.3 \pm 5.6 \dagger$ & $9.4 \pm 5.3$ & 0.98 \\
Training history (yrs) & $5.1 \pm 1.2^{*}$ & $5.5 \pm 2.9$ & 0.31 \\
\hline
\end{tabular}

Note. a.u. = arbitrary unit; NA = not applicable.

*Significantly different from men $(p<.01)$.

${ }^{\dagger}$ Significantly different from men $(p<.05)$.

0.95-0.97) and valid for testing anaerobic performance in both adults and children (26) with a mean anaerobe contribution of $81.4 \%$ measured by gas analysis (2). In our laboratory setting, the routinely assessed technical errors of measurement (\%TEM) of PP and MP on 2 different occasions are $3.1 \%$ and $1.8 \%$, respectively.

Tanner stages were used to assess sexual maturation (49) of boys participating in this study. The guardians were given line drawings and written explanations of each developmental stage using pubic hair in boys. A researcher who was well familiar with the Tanner stage criteria was available to answer questions. All laboratory procedures took place in the presence of 1 parent and two researchers but without presence of any other team members or coaches.

Height was measured to the nearest $1 \mathrm{~mm}$ using a stadiometer (Seca 214, Hamburg, Germany), body mass was measured to the nearest of $0.1 \mathrm{~kg}$ using a calibrated scale (Seca 769, Hamburg, Germany). Lean body mass and \% body fat were determined via whole body bioimpedance analysis using Nutrigard-S (Data Input, Darmstadt). All assessments were performed using 4 standard surface electrodes (tetra polar) attached on the participant's right hand and foot.

All tests were performed in an environmentally controlled laboratory (ambient temperature: $23 \pm 1{ }^{\circ} \mathrm{C}$; relative humidity, $44 \pm 3 \%$ ). To prevent circadian influences especially on salivary cortisol (28), all tests were conducted between $5 \mathrm{pm}$ and $7 \mathrm{pm}$. Participants were instructed to refrain from drinking (except water) and eating for at least 2 hours before testing. Participants were not allowed to perform strenuous activities, consume coffee, alcohol, or tobacco $24 \mathrm{hr}$ prior testing.

In accordance with the standardized instructions for the Wingate Anaerobic Test (26), participants completed a ten-min warm-up before the sprints at $2.0 \mathrm{~W} / \mathrm{kg}$ body mass and 60-90 rpm and then recovered for $3 \mathrm{~min}$. Subsequently, participants performed the 430 -s cycle sprints with 2-min active recovery between sprints. All participants were instructed and encouraged to perform each of the 30-s cycle sprints at maximum intensity (26). The cadence was electronically controlled at $120 \mathrm{rpm}$ (isokinetic mode). The active recovery between sprints consisted of cycling at $1.5 \mathrm{~W} / \mathrm{kg}$ body mass and $60-90$ $\mathrm{rpm}$. After the last sprint, participants cycled for $3 \mathrm{~min}$ at $1.5 \mathrm{~W} / \mathrm{kg}$ body mass to prevent vagal faint. Finally, all athletes rested for $27 \mathrm{~min}$ in a seated position while being supervised.

\section{Test Parameters}

Saliva samples were obtained using Salivettes (Sarstedt, Nümbrecht, Germany) before the warm-up and $30 \mathrm{~min}$ after the last sprint to capture the peak exercise-induced cortisol concentration $(29,50,52)$. Following intense exercise, peak serum, and salivary cortisol concentrations can be found 30 min post exercise in young male taekwondo athletes (9) and trained adults performing 4 $\times 30$-s Wingate Anaerobic Tests (52). Measuring cortisol in saliva clearly reflect the free and thus biological active fraction of cortisol operating in the entire human body-glucocorticoid- and mineralocorticoid receptors are expressed in various tissues such as the brain, immune cells, muscles, or the heart (48). Furthermore, taking saliva samples is noninvasive (compared with measuring lactate) and does not involve electronic apparatus and instruments (compared with measuring heart rate). This exceptionally qualifies salivary cortisol as a measure of stress in field studies and studies where the permanent presence of an expert is not possible or feasible.

Participants were instructed to chew on the cotton roll for $3 \mathrm{~min}$ to stimulate saliva production. After chewing, the cotton rolls were placed in the plastic container of the Salivette and stored at $-20^{\circ} \mathrm{C}$ until analysis. Salivary cortisol (nmol/l) was measured using a commercial enzyme linked immunosorbent assay (ELISA; IBL 
Diagnostics, Hamburg, Germany) on a fully automated analyzer (NEXGen, Adaltis, Freiburg, Germany) with low intra- and interassay coefficients of variance $(<5 \%$ and $<7 \%$, respectively). The coefficient of variation in repeated measures for salivary cortisol concentration has been shown to be $2.2 \%$. All samples were measured in duplicates, and the mean of the 2 values was used for further analysis.

Capillary blood samples $(20 \mu \mathrm{l})$ from the hyperaemic right earlobe were taken before and after the warm-up, after each sprint, and 2 and every 5 min after the last sprint for $30 \mathrm{~min}$. All blood samples were haemolysed in 2-ml microtest tubes, and lactate concentrations were determined via an amperometric-enzymatic procedure using EKF BIOSEN C-Line Sport (EKF Diagnostics $\mathrm{GmbH}$, Barleben, Germany). The coefficient of variation in repeated measures for blood lactate concentration is $1.3 \%$ at $12 \mathrm{mmol} / \mathrm{l}$.

Heart rate was continuously recorded during all sprints in 0.5-s intervals using the Polar RS 800 telemetric heart monitor (Polar, Kempele, Finland). The individual's peak heart rate $\left(\mathrm{HR}_{\text {peak }}\right)$ was defined as the highest values reached during any 0.5 -s interval.

Oxygen uptake and carbon dioxide production were recorded breath-by-breath using the spirometric system Meta Max 3B (Cortex Biophysik GmbH, Leipzig, Germany) for all sprints including warm-up and 30-min recovery. Before each test, the gas and volume analysers were calibrated according to the manufacturer's instructions employing high precision gas $\left(15 \% \mathrm{O}_{2} ; 5 \% \mathrm{CO}_{2}\right.$ in $\mathrm{N}$; Cortex Biophysik GmbH, Leipzig, Germany) and a 3 L syringe (Cortex Biophysik GmbH, Leipzig, Germany). All respiratory data were averaged over 30-s intervals, and the highest value of oxygen uptake was considered $\mathrm{VO}_{2 \text { peak. }}$.

Peak power (PP) and mean power (MP) were recorded every $0.5 \mathrm{~s}$ during all sprints and defined as the highest mechanical power exerted during the test and as the mean mechanical power maintained throughout the 30-s sprints, respectively. The fatigue index (FI) was defined as the degree of decline in power output during the sprints calculated as:

$$
\mathrm{FI}=(\mathrm{PP}-\mathrm{Minimum} \text { power }) / \mathrm{PP} \cdot 100)(26) .
$$

$\mathrm{PP}$ and MP were normalized to lean body mass $\left(\mathrm{P}_{\text {rel }}\right)$.

\section{Data Processing and Statistical Analysis}

All statistical tests were performed in SPSS Statistics 18 (SPSS Inc., Chicago, IL, USA). All data are reported as mean values and standard deviations $(S D)$. Physiological data were checked for normality. Differences in anthropometric data between boys and men were compared using independent samples Student's $t$ tests. A repeated measure analysis of variance (RM-ANOVA) was used to detect differences in the effect of exercise on salivary cortisol level, heart rate, blood lactate and performance indices between boys and men with group (boys versus men) as between-subject factor and time (pre- versus posttest) as within-subject factor. The effect size Cohen's $d$, defined as (difference between the means)/standard deviation) was calculated for all variables. The thresholds for small, moderate, and large effects were 0.20, 0.50, and 0.80 , respectively (11). The significance level was set a priori to $\alpha=0.05$.

\section{Results}

\section{Salivary Cortisol and Blood Lactate Levels}

After the 30-min recovery, salivary cortisol concentrations were higher than at baseline in both groups $(p<$ .01 ; Figure 1). Salivary cortisol concentrations increased in boys from $5.55 \pm 3.3 \mathrm{nmol} / 1$ to $15.13 \pm 9.7 \mathrm{nmol} / \mathrm{l}$ $(+173 \%)$ and in men from $7.07 \pm 4.7 \mathrm{nmol} / \mathrm{l}$ to 19.19 $\pm 12.7 \mathrm{nmol} / \mathrm{l}(+171 \%)$. At baseline and after recovery, salivary cortisol levels did not differ between boys and men (baseline: $\mathrm{d}=0.37$; after recovery: $\mathrm{d}=0.36 ; p=.21$; $\mathrm{F}=1.62 ; \mathrm{df}=1)$ at any time point $(p=.41 ; \mathrm{F}=.69 ; \mathrm{df}=1$; Figure 1). Peak blood lactate concentrations and lactate values during the HIIT in boys were significantly lower than in men except at prewarm-up and after the first sprint (peak concentration: $p<.01 ; \mathrm{d}=1.12$; HIIT: $p<.01$; pre: $\mathrm{d}=0$; post warm up: $\mathrm{d}=0.986$; sprint $1: \mathrm{d}=0.45$; sprint $2: \mathrm{d}=0.78$; sprint $3: \mathrm{d}=1.07$; sprint $4: \mathrm{d}=1.18 ; 2$-min posttest: $\mathrm{d}=1.36 ; 5$-min posttest: $\mathrm{d}=1.44 ; 10$-min posttest: $\mathrm{d}=1.63 ; 15$-min posttest: $\mathrm{d}=1.60 ; 20$-min posttest: $\mathrm{d}=1.41 ; 25$-min posttest: $\mathrm{d}=1.32 ; 30$-min posttest: $\mathrm{d}=$ 1.20; Figure 2). During HIIT, no significant difference in time of appearance of peak blood lactate concentration $\left(\mathrm{TBLC}_{\text {peak }}\right.$ ) was observed between boys and men (boys: 01:04 \pm 01:19 min posttest; men: 01:31 \pm 01:24 min posttest; $p>.05)$.

\section{Heart Rate and Oxygen Uptake}

During all 4 sprints, the $\mathrm{HR}_{\text {peak }}$ ranged from 172 to 215 beats/min in boys and from 159 to 202 beats/min in men. Mean heart rates were higher in boys than in men $(p<$ .01 ; Table 2). The mean heart rate increased from the first to the second sprint both in boys and in men $(p<.001)$. The $\% \mathrm{HR}_{\text {peak }}$ did not differ between boys and men $(p<$ .001; Table 2).

Relative $\mathrm{VO}_{2 \text { peak }}$ and absolute $\mathrm{VO}_{2 \text { peak }}$ were lower in boys than in men $\left(\mathrm{VO}_{2 \text { peak }}: p<.05 ; \mathrm{d}=0.71\right.$; absolute $\mathrm{VO}_{2 \text { peak }}: p<.01 ; \mathrm{d}=4.18$; Table 1$)$.

\section{Performance Indices}

The PP relative to lean body mass for the boys was $16.7 \%$ lower than that for men during all sprints $(p<.001$; Table 3). In boys, PP decreased from sprint 1 to sprint 4 by -9.9 $\pm 13.7 \%$. In contrast, the decrease in PP from sprint 1 to sprint 4 was $-20.5 \pm 11.5 \%$ in men, a difference reaching statistical significance $(p<.01)$. The MP relative to body mass for boys was more than $10.6 \%$ lower than that for men during all for sprints $(p<.001$; Table 3$)$. The decrease in MP from sprint 1 to sprint 4 in boys and 


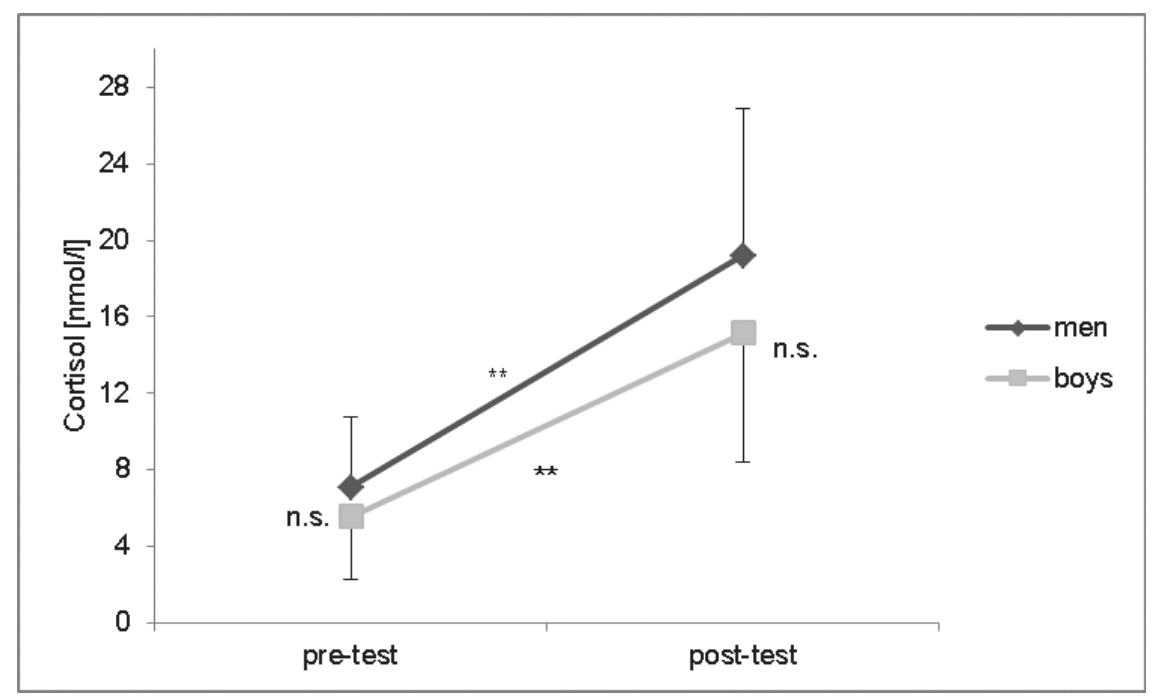

Figure 1 - Mean $( \pm \mathrm{SD})$ salivary cortisol concentration in boys (square) and men (diamond) measured before warm-up (pre-test) and 30 minutes after the last sprint (post-test). ${ }^{*}$ Significant pre- to post-test changes in both groups $(p<.01) . \mathrm{n}$. s. $=$ not significant $(\mathrm{p}>.05)$.

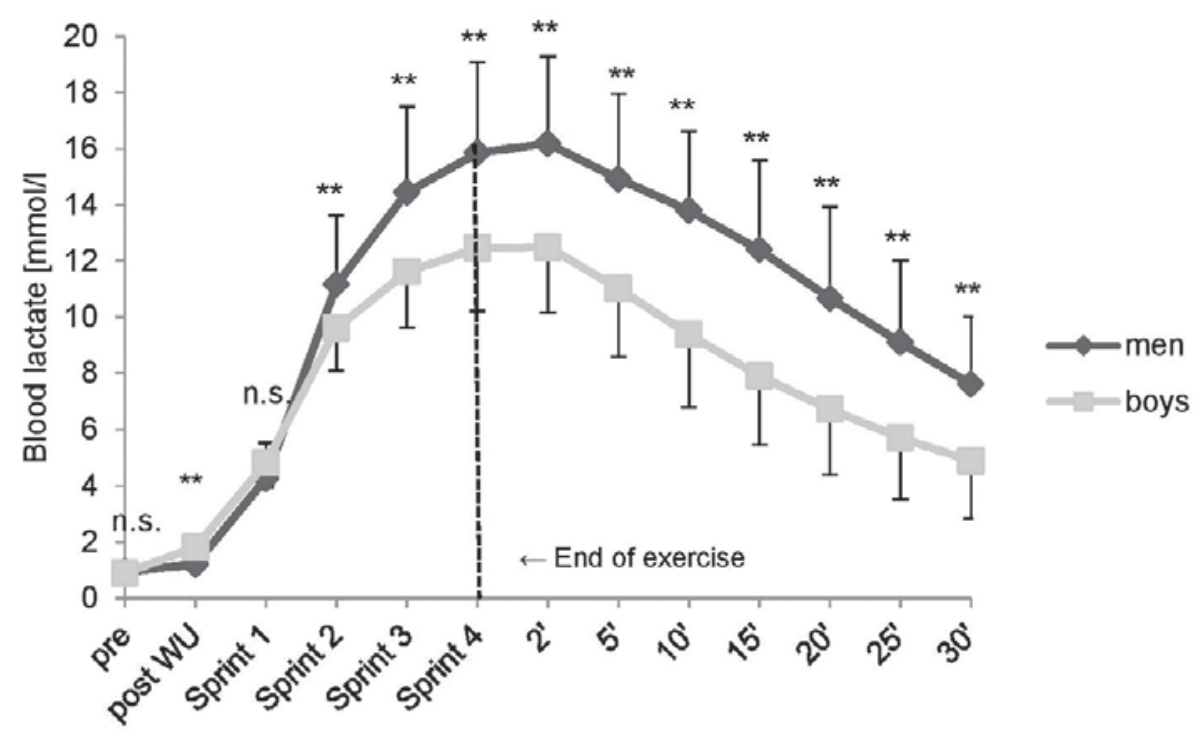

Figure $2-$ Mean $( \pm \mathrm{SD})$ blood lactate concentration over time from pre-test to 30 minutes after the last sprint in boys (square) and men (diamond). WU $=$ warm-up. $* *$ Significant difference between groups $(p<.01)$.

men was different but failed to reach level of significance (boys: $-21.2 \pm 11.7 \%$; men: $-25.3 \pm 11.6 \% ; p>.05$ ).

The FI did not differ between boys and men during all sprints $(p>.05$; Table 3$)$.

\section{Discussion}

The purpose of this study was to determine the effect of a single HIIT session on salivary cortisol, blood lactate levels, heart rate, oxygen uptake, and performance in trained 11-year-old boys compared with trained male adults to evaluate the hormonal and metabolic demands of HIIT. Although HIIT has become increasingly popular in high level youth sport, to the best of our knowledge this is the first study focusing on the hormonal response of trained children to HIIT. The concentrations of physiological stress markers were significantly elevated after HIIT in both groups indicating high physiological exertion. Compared with results reported in the literature $(4,13,37,39,51)$, the cortisol increase after HIIT was comparatively high with a more than twofold increase from pre warm-up to posttest in boys and men $(+173 \%$ and $+171 \%$, respectively). In this study mean and peak 
Table 2 Mean \pm SD of Mean Absolute Heart Rate and Mean Relative Heart Rate for Sprint 1 to 4 in Boys and Men

\begin{tabular}{lcccc}
\hline & Sprint 1 & Sprint 2 & Sprint 3 & Sprint 4 \\
\hline Boys (b/min) & $167 \pm 14^{*}$ & $175 \pm 10^{*}$ & $175 \pm 10^{*}$ & $178 \pm 10^{*}$ \\
Men (b/min) & $155 \pm 15$ & $164 \pm 13$ & $163 \pm 13$ & $164 \pm 19$ \\
Effect size d & 0.857 & 0.995 & 1.034 & 0.922 \\
Boys (\%) & $84.9 \pm 4.7$ & $89.1 \pm 3.7$ & $89.3 \pm 4.2$ & $90.4 \pm 3.7$ \\
Men (\%) & $85.6 \pm 3.8$ & $90.5 \pm 2.8$ & $90.1 \pm 4.3$ & $91.3 \pm 3.0$ \\
Effect size d & 0.16 & 0.42 & 0.18 & 0.26 \\
\hline
\end{tabular}

Note. \%HRpeak = highest heart rate reached.

*Significantly different from men $(p<.01)$.

Table 3 Mean \pm SD of Performance Indices Peak Power, Mean Power, and Fatigue Index for Sprint 1 to 4 in Boys and Men

\begin{tabular}{lcccc}
\hline & Sprint 1 & Sprint 2 & Sprint 3 & Sprint 4 \\
\hline Peak power & & & \\
Boys (W/kg lean body mass) & $11.1 \pm 1.4$ & $10.6 \pm 1.2$ & $10.0 \pm 1.2$ & $10.0 \pm 1.5$ \\
Men (W/kg lean body mass) & $15.1 \pm 1.7^{*}$ & $13.4 \pm 1.4^{*}$ & $12.4 \pm 1.9^{*}$ & $12.0 \pm 1.7^{*}$ \\
Effect size d & 2.56 & 2.14 & 1.51 & 1.24 \\
Mean power & & & $6.7 \pm 0.8$ \\
Boys (W/kg lean body mass) & $8.5 \pm 0.7$ & $7.6 \pm 0.6$ & $6.8 \pm 0.7$ & $7.4 \pm 0.9^{*}$ \\
Men (W/kg lean body mass) & $9.9 \pm 0.8^{*}$ & $8.5 \pm 0.6^{*}$ & $7.7 \pm 1.0^{*}$ & 0.82 \\
Effect size d & 1.86 & 1.50 & 1.04 & $59.0 \pm 9.8$ \\
Fatigue index & & & $5.8 \pm 11.6$ \\
Boys (\%) & $50.8 \pm 13.8$ & $59.0 \pm 10.7$ & $59.4 \pm 8.1$ \\
Men (\%) & $55.1 \pm 10.5$ & $57.1 \pm 8.1$ & $57.8 \pm 9.4$ & 5.8 \\
Effect size d & 0.35 & 0.20 & 0.15 & 0.24 \\
\hline
\end{tabular}

*Significant difference between boys and men $(p<.001)$.

blood lactate concentration, oxygen uptake, performance and decrease of performance (peak power) were lower, and heart rate was higher in boys than in adult male athletes during HIIT, while there was no difference in the fatigue index between groups.

Looking at previous results, types of physical exercise other than HIIT result in smaller cortisol increases postexercise. For instance, serum cortisol levels increased by $62 \%$ after long-duration physical exercise with moderate intensity in trained men (51). Similarly, Benitez-Sillero et al. (4) measured an increase in salivary cortisol concentrations by $70 \%$ in prepubertal boys and by $105 \%$ in pubescent boys after a $20-\mathrm{m}$ shuttle run test (4). Di Luigi et al (13) showed a $12.4 \%$ increase in salivary cortisol in 13.3-year-old soccer players after 90 min of combined soccer training at medium to highintensity (13). In addition, salivary cortisol levels in males increased by $50 \%$ following a $\mathrm{VO}_{2 \max }$ test (37). Even after an intensive and demanding taekwondo fight simulation, the increase in serum cortisol in adolescent taekwondo athletes was only $30 \%$ in males and $11 \%$ in females (39). The cortisol increase in our study is in agreement with the results reported by Capranica et al. (2012) who focused on the hormonal response in young boys (10.4 \pm 0.2 years) performing a taekwondo competition during a tournament (9). However, in taekwondo and fighting, the reported increases in cortisol could also be at least partly attributed to the high levels of aggression during combat maneuvers rather than to physical exertion (9). Thus, the impact of HIIT on the hormonal response in young athletes appears to be more pronounced compared with other physical stressors as described in the literature $(4,13,37,39,50)$.

Our results further indicate that HIIT is highly stressful for boys and male adults and may initiate a predominantly catabolic hormonal response. Several studies have investigated the interplay between the HPA axis, the ANS and the immune system (27). Recent evidence 
points toward an intricate relation between hormonal and sympathetic activity and immune responses especially during stress (for a review see 12,34). Consequently, HPA axis as well as autonomic deregulation may contribute to an inflammatory diathesis $(23,40)$ resulting in, for example, increased acute common cold symptoms and reduced performance. In addition, baseline levels of salivary cortisol in our study were similar in boys and men indicating that the cortisol concentrations at rest in the late afternoon do not depend on sexual maturation. This is in contrast to Di Luigi et al $(13,14)$ who reported a positive correlation between resting salivary cortisol concentrations and age during puberty $(13,14)$.

The high peak blood lactate concentrations after HIIT in boys and men confirmed that the exercise in this study was indeed high-intensity interval training. Significant differences between boys and men were established after the 2nd sprint and persisted until 30 min after testing. The boys showed considerably lower blood lactate values than the men group, but no difference in time of appearance of individual peak blood lactate concentration was found. Faster appearance of peak blood lactate concentrations following one single high intensive exercise in children has also been observed in previous studies $(3,16)$ and have been attributed to dimensional differences that result in shorter intramuscular perfusion distances and cardiovascular circulation times $(16,19)$. Following multiple bouts of high intensive exercise, no differences in time of appearance of peak blood lactate concentrations were observed between children and adults (41). Lower blood lactate concentrations in children compared with adults following intensive exercise are well documented in the literature. Ratel et al (41) reported lower lactate concentrations in boys $(8.5 \pm 2.1 \mathrm{mmol} / \mathrm{l})$ than in adults $(15.4 \pm 2.0 \mathrm{mmol} / \mathrm{l})$ after repeated cycling sprints (41) Other studies reported similar findings in postexercise blood and muscle lactate concentrations $(3,16,18,22)$. Various reasons for diminished maximal blood lactate concentration in children are discussed. Possible explanations include increased clearance of lactate from blood (3) or better regulation of hydrogen ion and a faster ventilatory regulation $(41,43)$. Moreover, the distribution of muscle fiber type may influence lactate levels with children having higher percentages of type I muscle fibers compared with young adults (30). type I muscle fibers show a higher density of type I monocarboxylate transporters (MCT 1: proteins that mediate the membrane transport of lactate and $\mathrm{H}^{+} ; 38$ ). Hence, the transport of lactate and $\mathrm{H}^{+}$ions by MCT1s across the membrane of type I muscle fibers is higher in children than in adults (43). Furthermore, it has been suggested that children under-use type-II motor units, thus mimicking or accentuating differential muscle composition as summarized in a recent review (15).

Despite the differences in blood lactate concentrations between boys and men, high blood lactate levels reflect the high exertion induced by HIIT. Reports of blood lactate concentrations in children after HIIT vary between $7.0 \mathrm{mmol} / \mathrm{l}$ and $8.6 \mathrm{mmol} / \mathrm{l}(41,47)$, which are lower than values reported in our study. Only 1 study found comparable high peak blood lactate values (10.7 $\mathrm{mmol} / \mathrm{l})$ in prepubertal boys following a single Wingate Anaerobic Test (16). However, peak blood lactate concentrations in boys in the current study $(12.5 \mathrm{mmol} / \mathrm{l})$ are still considerably higher as described by Dotan et al. (16). This discrepancy may be attributed to the high fitness level of the boys and the more demanding HIIT protocol in our study. Moreover, biological age and maturation can also account for high blood lactate concentrations in boys. Of note, $4 \%$ of boys showed Tanner's stage 1 , $87 \%$ showed Tanner's stage 2, and 9\% showed Tanner's stage 3. It is likely that boys in Tanner Stage 1 may have displayed lower blood lactate concentrations and therefore the difference in blood lactate concentrations between younger or less mature boys and men would be larger as actually shown in the current study. The blood lactate concentrations for trained men in our study are similar to those reported in the literature indicating blood lactate concentrations following 4 Wingate Anaerobic Test in trained men of $12.8 \pm 2.4 \mathrm{mmol} / \mathrm{l}$ (52). The boys in the current study were $11.5 \pm 0.8$ years old and, as already mentioned, showed Tanner stages 1 through 3 . Thus, some of the boys were already advanced in their maturation what might have resulted in smaller childadult differences than would have been observed with even younger boys. Moreover, since the boys were very well trained one might wonder whether their anaerobic capacity and glycolytic response could be attributed to their training and maturational age, or possibly to selection bias as well. As a consequence, reported results may underestimate the true boy-man difference in responses of saliva cortisol and blood lactate concentrations to HIIT.

The high percentage of $\mathrm{HR}_{\text {peak }}$ further demonstrates the high effort during the HIIT in boys and men. Higher heart rates in boys than in men throughout the 4 sprints are in agreement with previous evidence showing that children generally exhibit higher heart rates than adults during maximal exercise (45). Furthermore, the adult male group included mainly athletic trained adults who generally have lower heart rates than sedentary individuals and children, particularly during exercise (1).

In all 4 sprints, boys showed significantly lower peak and mean power output than men. We also observed a lower decrease of PP from Sprint 1 to Sprint 4 in boys compared with men which corresponds to a better fatigue resistance in boys as shown in previous studies $(19,41,43)$. The lower performance indices $(3,18)$ and the better fatigue resistance in boys $(41,43)$ are in agreement with the literature and reflect increasing maximal anaerobic power and capacity (18) as well as a decreasing fatigue resistance with growth and development $(19,43)$. However, the exact mechanisms for reduced anaerobic power and capacity as well as for the improved fatigue resistance in children are not yet fully understood. Falk and Dotan (19) suggested that children are more limited in recruiting higher-hierarchy motor units and therefore rely more on lower-hierarchy motor units which results in lower shortterm muscle power and a reduced fatigue (19). 
Some methodological considerations concerning the 4 repeated 30-s all-out procedure are worth noting. Although all of our participants were accustomed to highintensity exercise, they rated all 4 cycle sprints as very intense, being both physically demanding and mentally challenging. Therefore, some of the experienced adult athletes may have employed a pacing strategy during the $430 \mathrm{~s}$ all-out tests, as seen in the lower fatigue index in men compared with boys (Table 3 ). However, the mean fatigue index between boys and men did not differ and all participants started the test with an all-out effort, which was a prerequisite for this procedure.

\section{Conclusions}

This study is the first experimental study to examine the exercise-related metabolic and hormonal stress caused by 4 all-out cycle sprints in very young athletes. The significant increase in salivary cortisol, blood lactate concentrations, and heart rate suggests a high cardiorespiratory, metabolic, and hormonal response to HIIT in 11-year-old boys. Since this study investigated only the acute response to one single HIIT session, future studies investigating also short-term recovery and 12 to $48 \mathrm{hr}$ post exertion levels of physiological markers are highly warranted. Given the fact that HIIT might be regularly used within training programs, future studies clearly need to address the effects of repeated and excessive HIIT sessions. Considering the allostatic load model (32) as a theoretical framework to explain consequences, longterm interventions comprising repeated and excessive HIIT sessions may lead to a repeated high HPA axis activity. In the long run, this might lead to an inflammatory diathesis $(23,40)$ ultimately increasing the risk of acute common cold symptoms and reduced performance. Thus, future research is needed to investigate the hormonal responses in children following as well as consequences of longterm HIIT sessions.

\section{Acknowledgments}

The authors would like to thank the athletes for their participation, the Karlsruher Sport Club (KSC) for its assistance and support in study organization, Dr. Rainer Neumann for his advice and active support during the experimental sessions, and PD Dr. Annegret Mündermann for her writing assistance on behalf of the authors. The corresponding author would like to thank the Ernst Ludwig Ehrlich Studienwerk e.V. for the PhD stipend. The authors declare that they have no conflict of interest.

\section{References}

1. Astrand PO, Rodahl K. Textbook of Work Physiology, 3rd ed. New York: McGraw-Hill, 1986.

2. Beneke R, Pollmann C, Bleif I, Leithäuser RM, Hütler M. How anaerobic is the Wingate Anaerobic Test for humans? Eur J Appl Physiol. 2002; 87(4-5):388-392. PubMed doi:10.1007/s00421-002-0622-4
3. Beneke R, Hütler M, Jung M, Leithäuser RM. Modeling the blood lactate kinetics at maximal short-term exercise conditions in children, adolescents, and adults. $J$ Appl Physiol. 2005; 99(2):499-504. PubMed doi:10.1152/japplphysiol.00062.2005

4. Benitez-Sillero JD, Perez-Navero JL, Tasset I, Guillen-Del Castillo M, Gil-Campos M, Tunez I. Influence of intense exercise on saliva glutathione in prepubescent and pubescent boys. Eur J Appl Physiol. 2009; 106(2):181-186. PubMed doi:10.1007/s00421-009-1004-y

5. Boisseau N, Delamarche P. Metabolic and hormonal responses to exercise in children and adolescents. Sports Med. 2000; 30(6):405-422. PubMed doi:10.2165/00007256-200030060-00003

6. Budde H, Voelcker-Rehage C, Pietrassyk-Kendziorra S, Machado S, Ribeiro P, Arafat AM. Steroid hormones in the saliva of adolescents after different exercise intensities and their influence on working memory in a school setting. Psychoneuroendocrinology. 2010; 35(3):382-391. PubMed doi:10.1016/j.psyneuen.2009.07.015

7. Budde H, Windisch C, Kudielka BM, Voelcker-Rehage C. Saliva cortisol in school children after acute physical exercise. Neurosci Lett. 2010; 483(1):16-19. PubMed doi:10.1016/j.neulet.2010.07.036

8. Burgomaster KA, Howarth KR, Phillips SM, et al. Similar metabolic adaptations during exercise after low volume sprint interval and traditional endurance training in humans. J Physiol. 2008; 586(1):151-160. PubMed doi:10.1113/jphysiol.2007.142109

9. Capranica L, Lupo C, Cortis C, Chiodo S, Cibelli G, Tessitore A. Salivary cortisol and alpha-amylase reactivity to taekwondo competition in children. Eur J Appl Physiol. 2012; 112(2):647-652. PubMed doi:10.1007/s00421-0112023-Z

10. Chrousos GP. Stress and disorders of the stress system. Nat Rev Endocrinol. 2009; 5(7):374-381. PubMed doi:10.1038/nrendo.2009.106

11. Cohen J. Statistical power analysis for the behavioral sciences, 2nd ed. Hillsdale, NJ: Lawrence Erlbaum Associates, 1988.

12. Dhabhar FS, Malarkey WB, Neri E, McEwen BS. Stressinduced redistribution of immune cells-from barracks to boulevards to battlefields: a tale of three hormonesCurt Richter Award winner. Psychoneuroendocrinology. 2012; 37(9):1345-1368. PubMed doi:10.1016/j. psyneuen.2012.05.008

13. Di Luigi L, Baldari C, Gallotta MC, et al. Salivary steroids at rest and after a training load in young male athletes: relationship with chronological age and pubertal development. Int J Sports Med. 2006; 27(9):709-717. PubMed doi:10.1055/s-2005-872931

14. Di Luigi L, Guidetti L, Baldari C, et al. Cortisol, dehydroepiandrosterone sulphate and dehydroepiandrosterone sulphate/cortisol ratio responses to physical stress in males are influenced by pubertal development. J Endocrinol Invest. 2006; 29(9):796-804. PubMed doi:10.1007/BF03347373

15. Dotan R, Mitchell C, Cohen R, Klentrou P, Gabriel D, Falk B. Child-adult differences in muscle activation-a review. Pediatr Exerc Sci. 2012; 24(1):2-21. PubMed 
16. Dotan R, Ohana S, Bediz C, Falk B. Blood lactate disappearance dynamics in boys and men following exercise of similar and dissimilar peak-lactate concentrations. $J$ Pediatr Endocrinol Metab. 2003; 16(3):419-429. PubMed doi:10.1515/JPEM.2003.16.3.419

17. Eliakim A, Portal S, Zadik Z, et al. The effect of a volleyball practice on anabolic hormones and inflammatory markers in elite male and female adolescent players. $J$ Strength Cond Res. 2009; 23(5):1553-1559. PubMed doi:10.1519/JSC.0b013e3181aa1bcb

18. Falgairette G, Bedu M, Fellmann N, Van-Praagh E, Coudert J. Bio-energetic profile in 144 boys aged from 6 to 15 years with special reference to sexual maturation. Eur J Appl Physiol Occup Physiol. 1991; 62(3):151-156. PubMed doi:10.1007/BF00643734

19. Falk B, Dotan R. Child-adult differences in the recovery from high-intensity exercise. Exerc Sport Sci Rev. 2006; 34(3):107-112. PubMed doi:10.1249/00003677200607000-00004

20. Gibala MJ, Little JP. Just HIT it! A time-efficient exercise strategy to improve muscle insulin sensitivity. J Physiol. 2010; 588(Pt 18):3341-3342. PubMed doi:10.1113/ jphysiol.2010.196303

21. Hackney AC, Viru M, VanBruggen M, Janson T, Karelson K, Viru A. Comparison of the hormonal responses to exhaustive incremental exercise in adolescent and young adult males. Arq Bras Endocrinol Metabol. 2011; 55(3):213-218. PubMed doi:10.1590/S000427302011000300006

22. Hebestreit H, Meyer F, Htay-Htay, Heigenhauser GJ, Bar-Or O. Plasma metabolites, volume and electrolytes following 30-s high-intensity exercise in boys and men. Eur J Appl Physiol Occup Physiol. 1996; 72(5-6):563-569. PubMed doi:10.1007/BF00242291

23. Heim C, Ehlert U, Hellhammer DH. The potential role of hypocortisolism in the pathophysiology of stress-related bodily disorders. Psychoneuroendocrinology. 2000; 25(1):1-35. PubMed doi:10.1016/S03064530(99)00035-9

24. Helgerud J, Engen LC, Wisloff U, Hoff J. Aerobic endurance training improves soccer performance. Med Sci Sports Exerc. 2001; 33(11):1925-1931. PubMed doi:10.1097/00005768-200111000-00019

25. Helgerud J, Rodas G, Kemi OJ, Hoff J. Strength and endurance in elite football players. Int J Sports Med. 2011; 32(9):677-682. PubMed doi:10.1055/s-0031-1275742

26. Inbar O, Bar-Or O, Skinner JS. The Wingate Anaerobic Test, 8th ed. Champaign, IL: Human Kinetics, 1996.

27. Irwin MR, Cole SW. Reciprocal regulation of the neural and innate immune systems. Nat Rev Immunol. 2011; 11(9):625-632. PubMed doi:10.1038/nri3042

28. Kirschbaum C, Hellhammer DH. Salivary cortisol in psychoneuroendocrine research: recent developments and applications. Psychoneuroendocrinology. 1994; 19(4):313-333. PubMed doi:10.1016/03064530(94)90013-2

29. Leite RD, Prestes J, Rosa C, et al. Acute effect of resistance training volume on hormonal responses in trained men. $J$ Sports Med Phys Fitness. 2011; 51(2):322-328. PubMed
30. Lexell J, Sjöström M, Nordlund AS, Taylor CC. Growth and development of human muscle: a quantitative morphological study of whole vastus lateralis from childhood to adult age. Muscle Nerve. 1992; 15(3):404-409. PubMed doi:10.1002/mus. 880150323

31. Little JP, Safdar A, Wilkin GP, Tarnopolsky MA, Gibala MJ. A practical model of low-volume high-intensity interval training induces mitochondrial biogenesis in human skeletal muscle: potential mechanisms. J Physiol. 2010; 588(Pt 6):1011-1022. PubMed doi:10.1113/ jphysiol.2009.181743

32. McEwen BS. Stress, adaptation, and disease. Allostasis and allostatic load. Ann N Y Acad Sci. 1998; 840:33-44. PubMed doi:10.1111/j.1749-6632.1998.tb09546.x

33. McMillan K, Helgerud J, Macdonald R, Hoff J. Physiological adaptations to soccer specific endurance training in professional youth soccer players. Br J Sports Med. 2005; 39(5):273-277. PubMed doi:10.1136/bjsm.2004.012526

34. Nance DM, Sanders VM. Autonomic innervation and regulation of the immune system (1987-2007). Brain Behav Immun. 2007; 21(6):736-745. PubMed doi:10.1016/j. bbi.2007.03.008

35. Nieman DC. Upper respiratory tract infections and exercise. Thorax. 1995; 50(12):1229-1231. PubMed doi:10.1136/thx.50.12.1229

36. Nieman DC, Henson DA, Austin MD, Brown VA. Immune response to a 30-minute walk. Med Sci Sports Exerc. 2005; 37(1):57-62. PubMed doi:10.1249/01. MSS.0000149808.38194.21

37. O'Connor PJ, Corrigan DL. Influence of short-term cycling on salivary cortisol levels. Med Sci Sports Exerc. 1987; 19(3):224-228. PubMed

38. Pilegaard H, Terzis G, Halestrap A, Juel C. Distribution of the lactate/H+ transporter isoforms MCT1 and MCT4 in human skeletal muscle. Am J Physiol. 1999; 276(5 Pt 1):E843-E848. PubMed

39. Pilz-Burstein R, Ashkenazi Y, Yaakobovitz Y, et al. Hormonal response to Taekwondo fighting simulation in elite adolescent athletes. Eur J Appl Physiol. 2010; 110(6):1283-1290. PubMed doi:10.1007/s00421-010$1612-6$

40. Raison CL, Miller AH. When not enough is too much: the role of insufficient glucocorticoid signaling in the pathophysiology of stress-related disorders. Am J Psychiatry. 2003; 160(9):1554-1565. PubMed doi:10.1176/appi. ajp.160.9.1554

41. Ratel S, Duche P, Hennegrave A, van Praagh E, Bedu M. Acid-base balance during repeated cycling sprints in boys and men. J Appl Physiol. 2002; 92(2):479-485. PubMed

42. Ratel S. High-intensity and resistance training and elite young athletes. Med Sport Sci. 2011; 56:84-96. PubMed

43. Ratel S, Duché P, Williams CA. Muscle fatigue during high-intensity exercise in children. Sports Med. 2006; 36(12):1031-1065. PubMed doi:10.2165/00007256200636120-00004

44. Riddell MC. The endocrine response and substrate utilization during exercise in children and adolescents. $J$ Appl Physiol. 2008; 105(2):725-733. PubMed doi:10.1152/ japplphysiol.00031.2008 
45. Rowland TW. Children's exercise physiology, 2nd ed. Champaign: Human Kinetics, 2005.

46. Sperlich B, de Marées M, Koehler K, Linville J, Holmberg $\mathrm{H}$, Mester J. Effects of 5 weeks of high-intensity interval training vs. volume training in 14-year-old soccer players. J Strength Cond Res. 2011; 25(5):1271-1278. PubMed doi:10.1519/JSC.0b013e3181d67c38

47. Sperlich B, Zinner C, Heilemann I, Kjendlie P, Holmberg $\mathrm{H}$, Mester J. High-intensity interval training improves VO(2peak), maximal lactate accumulation, time trial and competition performance in 9-11-year-old swimmers. Eur J Appl Physiol. 2010; 110(5):1029-1036. PubMed doi:10.1007/s00421-010-1586-4

48. Stalder T, Kirschbaum C. Cortisol. In: Encyclopedia of Behavioral Medicine, M Gellman and JR Turner (Eds.). New York: Springer, 2013, pp. 507-512.

49. Tanner JM, Whitehouse RH. Clinical longitudinal standards for height, weight, height velocity, weight velocity, and stages of puberty. Arch Dis Child. 1976; 51(3):170179. PubMed doi:10.1136/adc.51.3.170

50. VanBruggen MD, Hackney AC, McMurray RG, Ondrak KS. The relationship between serum and salivary cortisol levels in response to different intensities of exercise. Int $J$ Sports Physiol Perform. 2011; 6(3):396-407. PubMed

51. Viru A, Karelson K, Smirnova T. Stability and variability in hormonal responses to prolonged exercise. Int J Sports Med. 1992; 13(3):230-235. PubMed doi:10.1055/s-2007-1021259

52. Wahl P, Mathes S, Köhler K, Achtzehn S, Bloch W, Mester J. Acute Metabolic, Hormonal, and Psychological Responses to Different Endurance Training Protocols. Horm Metab Res. 2013; 45(11):827-833. PubMed doi:10.1055/s-0033-1347242 